\title{
Suppressor determinants of mycobacteria and their potential relevance to leprosy
}

\author{
P M NYE, * J L STANFORD, * G A W ROOK, * \\ P LAWTON, ${ }^{*}$ M MACGREGOR, ${ }^{*}$ C REILY,* \\ D HUMBER, $\dagger$ P OREGE, $\ddagger$ C R REVANKAR,** \\ J TERENCIO DE LAS AGUAS§ \& P TORRES§ \\ * School of Pathology, Middlesex Hospital Medical School, London \\ W1; $\dagger$ Armauer Hansen Research Institute, P.O. Box 1005, Addis \\ Ababa, Ethiopia; $\dagger$ Alupe Leprosy Research Centre, P.O. Box 3, \\ Busia, Kenya; ** Bombay Leprosy Project, 6/27 Amar Bhuvan, Sion \\ (East), Bombay-400022, India; § Sanatorio de Fontilles, Alicante, \\ Spain
}

Accepted for publication 6 November 1985

Summary This paper extends our studies of the local and distant suppressions of skin-test responses to mixed mycobacterial reagents previously demonstrated in Nepal and Bombay. Several new mixtures were prepared, which included DEAE separated fractions of a sonicate of Mycobacterium vaccae (Vaccin). Local suppression was a major feature of the results in all the centres except Kopri in Bombay. All of the Vaccin fractions were capable of inducing local suppression. Distant suppression associated with all the fractions was observed at one of the Bombay centres, but not the other $(p<0.00001)$. In Kenya distant suppression also occurred at only one of the centres $(p<0.00003)$, but at this centre it was associated significantly with only 2 of the 5 fractions tested $(p<0 \cdot 001$ in each case).

Our results may well depend on geographical differences probably associated with the quantity and quality of sensitization by fast-growing environmental mycobacteria. The possibly essential part played by suppressor determinants within the fractions described in the initial infection with $M$. leprae and in the pathogenesis of multibacillary disease is discussed.

\section{Introduction}

The purposes of this paper and the three preceding it, ${ }^{1-3}$ have been to investigate the ability of mycobacteria to suppress cell-mediated responses to themselves or to other mycobacterial products injected at a distant site. This is relevant to 
leprosy since it may be the way in which the initial infection gets established, and in lepromatous leprosy it may be the fundamental mechanism underlying the socalled immune defects invariably present in that disease. Other aspects of suppression of immune mechanisms may prove to be of considerable use in immunotherapy. We have employed sonicates of cultivable species of mycobacteria in studies designed to determine how many different suppressor functions mycobacteria may exert and who is susceptible to them.

In our previous investigations of skin test responsiveness to mixed mycobacterial reagents, 2 distinct types of suppressor phenomena have been observed. The first involves local suppression of responses at the site of injection to a reagent prepared from 12 slow-growing mycobacterial species by the addition of a mixture of 12 fast-growing species. This type of local suppression was demonstrated in Nepal ${ }^{1}$ and in Bombay, ${ }^{2}$ and may be the mechanism by which a tiny infective inoculum of leprosy bacilli becomes established in the tissue.

The second type of suppression, which had been observed in Kopri Colony (Bombay) alone, involves distant suppression of response to the mixed slow grower reagent (SG) on one arm by injection of the same SG reagent mixed with a reagent prepared from a single fast grower on the other arm. The fast grower reagents associated with the second type of suppression included Chitin, Diernhoferin, Vaccin and Rhodesin (called group A) ${ }^{2}$. It was postulated that this type of suppression might be due to species specific determinants of these organisms. Its occurrence, therefore, would seem to depend on prior sensitization by the species concerned. If Mycobacterium leprae has determinants producing suppression of this type it could explain the development of lepromatous disease and the species specific aspects of the immune defect.

For the present study a sonicate of $M$. vaccae has been fractionated on a DEAE column and the individual fractions added to the SG mixture in order to determine which of them might be associated with suppressor activities. The system has been tested in 6 centres; Kopri Colony, and Vimala Dermatology Centre in Bombay, Alupe Leprosy Research Centre and Tumu Tumu Hospital in Kenya, Fontilles Sanatorium in Spain and AHRI/ALERT, Addis Ababa, Ethiopia.

\section{Materials and methods}

Persons tested included leprosy patients and staff in Bombay and Addis Ababa, and staff alone at the other centres. Each individual received 4 simultaneous intradermal tests, 2 on each forearm. All reagents used were at a concentration of $2 \mu \mathrm{g} / \mathrm{ml}$, and the dose injected was $0 \cdot 1 \mathrm{ml}$. The mean of 2 diameters of induration was recorded after $72 \mathrm{hr}$ and reactions of $2 \mathrm{~mm}$ or more were taken as positive.

Some of the reagents employed were the same batches as those used in our previous studies. These were the first 3 listed below and the first two of number 4 . 
1 SG: a mixed reagent prepared from 12 slow-growing species.

2 FG: a mixed reagent prepared from 12 fast-growing species.

$3 \mathrm{~F} / \mathrm{S}$ : an equal mixture of the 2 above.

4 An equal mixture of SG + Vaccin, SG + Chitin, SG + Leprosin A or one of 5 reagents consisting of equal volumes of SG together with DEAE column separated fractions of Vaccin.

Each person received the first 3 reagents and one of the group 4 reagents.

\section{Preparation of Vaccin fractions}

A $2 \cdot 5-\mathrm{cm}$ column was packed to a height of $35 \mathrm{~cm}$ with DEAE cellulose

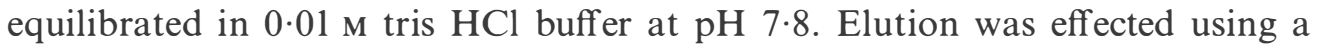
continuous tris molarity gradient to a final concentration of $1.0 \mathrm{M}$ tris. The eluent was collected in approximately $5-\mathrm{ml}$ volumes, and absorption was measured at a wavelength of $280 \mathrm{~nm}$. Tubes containing the peaks were pooled and passed through a $0 \cdot 22-\mu \mathrm{m}$ filter into presterilized dialysis tubing. The fractions were then concentrated and dialysed for 4 days at $4{ }^{\circ} \mathrm{C}$ against normal saline. Five of the fractions were obtained in sufficient quantities to allow the preparation of skin test reagents, these were F2, F4, F5, F6 and F7. The numbers indicate the order of elution from the column and correspond to the increasingly negative charge of the constituents. The protein strengths of the preparations were assessed and their concentrations adjusted to $2 \cdot 0 \mu \mathrm{g} / \mathrm{ml}$ with borate buffer, $\mathrm{pH} 8.0$.

The skin test reagents for the 4th site were prepared by mixing equal volumes of SG together with one of these fractions.

We have slightly changed our definitions of suppression. Local suppression was previously described only in Category 3 reactors but has now been expanded to include those in Category 1. Distant suppression of the SG reagent was defined as a response which is half or less of that to the $F / S$, but since the $F / S$ reagent itself may be suppressed, it is now compared with response to the $\mathrm{F} / \mathrm{S}$ or 4 th reagents.

The Fisher Exact Test has been employed for statistical analyses.

\section{Results}

A total of 528 individuals received skin tests of which 144 had BCG scars, which did not appear to influence the results. However this may need further evaluation.

Previous data has been examined in relation to the 3 categories of skin test responders. ${ }^{1}$ Category 1 contains individuals who produce positive reactions to all mycobacterial reagents. Category 2 respond to none of them at routine test concentration, while category 3 responders react to some reagents and not to others. However, categorization using reagents of the type presently under 
investigation may differ somewhat from those achieved using reagents prepared from single species. The numbers found in each category in the 6 centres are shown in Table 1.

There is a marked expansion of category 2 nonreactors at Vimala, Addis Ababa and Fontilles. In the first 2 cases this is at the expense of category 3 reactors but at Fontilles it results in total loss of category 1. Conversely Alupe has no category 2 nonresponders.

Table 2 gives the number, percentage positive and mean positive reaction sizes, together with their standard deviations in persons in categories 1 and 3 . As an example of the individual results obtained, those for the Kenyan centres of Alupe and Tumu Tumu are shown in Table 3. The figures in brackets are the results from a small investigation of the duration of SG suppression in individuals some 12 months after the first tests. Of the 15 people retested with SG alone, the 8 who previously had total SG suppression all gave positive responses at $72 \mathrm{hr}$ with an average area of induration of $6 \cdot 9 \pm 2.8 \mathrm{~mm}$.

When comparing the total percentages positive at the different centres, suppression of responses is associated with many of the reagents. Vimala, Tumu Tumu, AHRI/ALERT and particularly Fontilles show decreased responses to $\mathrm{F} / \mathrm{S}$ as compared with SG $(p<0 \cdot 002)$. The reverse was true at Kopri and Alupe $(p<0 \cdot 001)$. Similarly when responses to the 4 th reagents are compared with those to SG alone the reduction of responses is highly significant $(p<0.00005)$ in Alupe, Fontilles, Tumu Tumu and AHRI/ALERT. The difference is not significant at Vimala and the trend is reversed in Kopri $\left(p<5 \cdot 0 \times 10^{-15}\right)$.

The figures for the FG reagent indicate that the degree of sensitization varies considerably at the different centres, from $37 \%$ positivity at Vimala to $98 \%$ at Alupe. This high level of sensitization by fast growers may explain the lack of category 2 individuals at Alupe.

Table 1. The distribution of the 3 categories of skin test responders in the 6 centres.

\begin{tabular}{|c|c|c|c|c|}
\hline \multirow[b]{3}{*}{ Centres } & \multicolumn{4}{|c|}{ Categories of responders } \\
\hline & I & & II & III \\
\hline & all + & + ve & all -ve & mixed \\
\hline Kopri & $12 / 83$ & $14 \%$ & $8 / 83 \quad 10 \%$ & $63 / 83 \quad 76 \%$ \\
\hline Vimala & $4 / 46$ & $9 \%$ & $19 / 46 \quad 41 \%$ & $23 / 46 \quad 50 \%$ \\
\hline Alupe & $11 / 55$ & $20 \%$ & $0 / 55 \quad 0 \%$ & $44 / 55 \quad 80 \%$ \\
\hline Fontilles & $0 / 40$ & $0 \%$ & $16 / 40 \quad 40 \%$ & $24 / 40 \quad 60 \%$ \\
\hline Tumu Tumu & $4 / 38$ & $11 \%$ & $6 / 38 \quad 16 \%$ & $28 / 38 \quad 74 \%$ \\
\hline Addis Ababa & $24 / 266$ & $69 \%$ & $112 / 26642 \%$ & $130 / 26649 \%$ \\
\hline
\end{tabular}


Table 2. Number and percentage of positive reactors together with mean reaction sizes and standard deviations of individuals in skin test responder categories 1 and 3 at the 6 centres.

\begin{tabular}{|c|c|c|c|c|}
\hline \multirow[b]{2}{*}{ Centre } & \multicolumn{3}{|c|}{ Reagents tested in all persons } & \multirow{2}{*}{$\begin{array}{l}\text { Variable } \\
\text { fourth } \\
\text { reagents }\end{array}$} \\
\hline & SG & FG & $\mathrm{F} / \mathrm{S}$ & \\
\hline Kopri & $\begin{array}{c}24 / 75 \quad 32 \% \\
7 \cdot 7 \pm 5 \cdot 2\end{array}$ & $\begin{array}{c}30 / 75 \quad 40 \% \\
7 \cdot 0 \pm 3 \cdot 8\end{array}$ & $\begin{array}{c}44 / 75 \quad 59 \% \\
10 \cdot 7 \pm 6 \cdot 5\end{array}$ & $\begin{array}{l}69 / 75 \quad 92 \% \\
10 \cdot 8 \pm 4 \cdot 2\end{array}$ \\
\hline Vimala & $\begin{array}{l}23 / 27 \quad 85 \% \\
10 \cdot 8 \pm 3 \cdot 7\end{array}$ & $\begin{array}{c}10 / 27 \quad 37 \% \\
7 \cdot 2 \pm 3 \cdot 9\end{array}$ & $\begin{array}{l}6 / 27 \quad 22 \% \\
7 \cdot 3 \pm 4 \cdot 5\end{array}$ & $\begin{array}{c}20 / 27 \quad 74 \% \\
10 \cdot 6 \pm 3 \cdot 2\end{array}$ \\
\hline Alupe & $\begin{array}{c}33 / 55 \quad 60 \% \\
9 \cdot 0 \pm 3 \cdot 0\end{array}$ & $\begin{array}{c}54 / 55 \quad 98 \% \\
9 \cdot 0 \pm 2 \cdot 8\end{array}$ & $\begin{array}{l}53 / 55 \quad 96 \% \\
10 \cdot 6 \pm 2 \cdot 8\end{array}$ & $\begin{array}{c}12 / 55 \quad 22 \% \\
8 \cdot 3 \pm 3 \cdot 9\end{array}$ \\
\hline Fontilles & $\begin{array}{c}24 / 24100 \% \\
9 \cdot 9 \pm 3 \cdot 8\end{array}$ & $\begin{array}{c}16 / 24 \quad 67 \% \\
7 \cdot 8 \pm 2 \cdot 8\end{array}$ & $\begin{array}{r}0 / 24 \quad 0 \% \\
0\end{array}$ & $\begin{array}{l}5 / 24 \quad 21 \% \\
8.7 \pm 1.9\end{array}$ \\
\hline Tumu Tumu & $\begin{array}{l}29 / 3291 \% \\
11 \cdot 1 \pm 4 \cdot 5\end{array}$ & $\begin{array}{c}12 / 3238 \% \\
6 \cdot 0 \pm 2 \cdot 6\end{array}$ & $\begin{array}{c}10 / 3231 \% \\
9 \cdot 6 \pm 4.9\end{array}$ & $\begin{array}{c}10 / 3231 \% \\
8 \cdot 2 \pm 5 \cdot 6\end{array}$ \\
\hline AHRI/ALERT & $\begin{array}{c}133 / 15486 \% \\
9 \cdot 1 \pm 4 \cdot 0\end{array}$ & $\begin{array}{c}58 / 15438 \% \\
7 \cdot 2 \pm 3 \cdot 2\end{array}$ & $\begin{array}{c}98 / 15464 \% \\
8 \cdot 6 \pm 3 \cdot 2\end{array}$ & $\begin{array}{c}80 / 15452 \% \\
10 \cdot 2 \pm 4 \cdot 5\end{array}$ \\
\hline
\end{tabular}

Note that the percentages positive to $\mathrm{F} / \mathrm{S}$ are significantly lower than those to SG in Vimala, Fontilles, Tumu Tumu and AHRI/ALERT $(p<0.002)$ and that the reverse is the case in Kopri and Alupe $(p<0.001)$.

Of the 528 individuals tested, 266 produced positive skin test responses to the SG reagent. Thirty of these had received fractions of $M$. vaccae alone as the fourth reagent, to which a single positive response was recorded to F6 (1/9) with no reaction to F2 (0/11) or F5 (0/10). The local suppressions associated with the $\mathrm{F} / \mathrm{S}$ combination and with the mixed fourth reagents can be assessed in 232 persons (see Table 4), 111 of these showed local suppression to F/S (48\%) although there was a significant variation between places. Suppression at the fourth reagent sites was found in 7/39 who received the half dose of SG alone; $2 /$ 27 who received SG + Vaccin; 6/19 who received SG and Leprosin A; 3/21 who received SG + Chitin. These differences are not significant statistically. Suppression at the sites of the fourth reagents incorporating Vaccin fractions was found in $29 / 36$ who received $\mathrm{SG}+\mathrm{F} 2,11 / 17$ who received $\mathrm{SG}+\mathrm{F} 4,16 / 20$ who received $\mathrm{SG}+\mathrm{F} 5,23 / 28$ who received $\mathrm{SG}+\mathrm{F} 6$ and $20 / 25$ who received $\mathrm{SG}+\mathrm{F} 7$. Although not significantly different from each other all the fractions produced significantly more suppression than did the half dose of SG alone $(p<0.001)$ or any of the fourth reagents containing whole tuberculins. With regard to suppression associated with reagents including the fractions, there was a highly significant 
$152 \quad P M N y e$ et al.

Table 3. Mean responses in millimetres to the 4 skin test reagents tested on individuals at Alupe and Tumu Tumu in Kenya.

\begin{tabular}{|c|c|c|c|c|c|c|c|c|}
\hline \multirow{2}{*}{$\begin{array}{l}4 \text { th Reagent } \\
\text { constituents }\end{array}$} & \multicolumn{4}{|c|}{ ALUPE } & \multicolumn{4}{|c|}{ TUMU TUMU } \\
\hline & SG & FG & $\mathrm{F} / \mathrm{S}$ & 4 th & SG & FG & $\mathrm{F} / \mathrm{S}$ & 4 th \\
\hline \multirow[t]{8}{*}{$\mathrm{SG}+$ Saline } & 0 & 0 & 7 & 0 & 21 & 0 & 0 & $15 \cdot 5$ \\
\hline & $13 \cdot 5$ & 10 & 15 & 8 & 17 & $7 \cdot 5$ & $16 \cdot 5$ & 19 \\
\hline & 12 & 5 & 13 & 11 & 0 & 0 & 0 & 3 \\
\hline & $5 \cdot 5$ & $8 \cdot 5$ & $7 \cdot 5$ & 10 & 13 & 0 & 0 & $4 \cdot 5$ \\
\hline & 15 & 10 & 12 & 11 & 17 & 0 & $14 \cdot 5$ & 12 \\
\hline & 10 & 10 & 10 & 7 & 14 & $4 \cdot 5$ & $9 \cdot 5$ & 6 \\
\hline & 8 & 7 & 9 & 8 & 8 & 6 & $8 \cdot 5$ & $8 \cdot 5$ \\
\hline & $9 \cdot 5$ & 10 & 12 & 10 & $13 \cdot 5$ & 5 & $4 \cdot 5$ & $6 \cdot 5$ \\
\hline \multirow[t]{10}{*}{$\mathrm{SG}+\mathrm{F} 2$} & 12 & 12 & 12 & 10 & $15 \cdot 5$ & 0 & 0 & 0 \\
\hline & $9 \cdot 5(8)$ & 10 & 12 & 0 & 2 & 0 & 0 & 0 \\
\hline & $7 \cdot 5$ & 10 & 10 & 0 & 0 & 0 & 0 & 2 \\
\hline & 0 & 6 & 6 & 0 & $7 \cdot 5$ & $8 \cdot 5$ & $10 \cdot 5$ & 0 \\
\hline & $10(6 \cdot 5)$ & 12 & 10 & 0 & 15 & $10 \cdot 5$ & 15 & 0 \\
\hline & $11(10)$ & 10 & 12 & 0 & & & & \\
\hline & 7 & 6 & 12 & 3 & & & & \\
\hline & $14(7 \cdot 5)$ & 10 & 12 & 0 & & & & \\
\hline & $10(6)$ & $7 \cdot 5$ & 11 & 0 & & & & \\
\hline & 10 & 10 & 15 & 4 & & & & \\
\hline \multirow[t]{8}{*}{$\mathrm{SG}+\mathrm{F} 4$} & $10(14 \cdot 5)$ & 12 & 11 & 0 & $12 \cdot 5$ & 0 & 0 & 0 \\
\hline & 7 & 5 & 10 & 0 & $14 \cdot 5$ & 0 & 0 & 0 \\
\hline & 10 & 5 & 12 & 0 & $8 \cdot 5$ & 3 & 0 & 5 \\
\hline & $8(10)$ & 12 & $11 \cdot 5$ & 0 & $12 \cdot 5$ & 0 & 0 & 0 \\
\hline & 5 & 13 & 14 & 0 & & & & \\
\hline & 7 & 10 & 11 & 0 & & & & \\
\hline & 12 & $12 \cdot 5$ & 13 & 16 & & & & \\
\hline & 0 & 7 & 7 & 0 & & & & \\
\hline \multirow[t]{8}{*}{$\mathrm{SG}+\mathrm{F} 5$} & 0 & 12 & 12 & 0 & $13 \cdot 5$ & 0 & 0 & 0 \\
\hline & 3 & 11 & 10 & 0 & 6 & $5 \cdot 5$ & 0 & 0 \\
\hline & $0(9)$ & 6 & $12 \cdot 5$ & 0 & $10 \cdot 5$ & 0 & 0 & 0 \\
\hline & $0(4)$ & $10 \cdot 5$ & 10 & 0 & $12 \cdot 5$ & 0 & 0 & 0 \\
\hline & 0 & $9 \cdot 5$ & 10 & 0 & & & & \\
\hline & 0 & 12 & 12 & 0 & & & & \\
\hline & 0 & 10 & 11 & 0 & & & & \\
\hline & $0(6 \cdot 5)$ & 5 & $9 \cdot 5$ & 0 & & & & \\
\hline \multirow[t]{7}{*}{$\mathrm{SG}+\mathrm{F} 6$} & 0 & $5 \cdot 5$ & 13 & 0 & 2 & 0 & 0 & 0 \\
\hline & $0(3 \cdot 5)$ & 12 & 13 & 0 & 9 & 0 & 0 & 0 \\
\hline & 4 & 10 & $10 \cdot 5$ & 0 & $14 \cdot 5$ & 0 & 0 & 0 \\
\hline & $0(10)$ & 7 & 14 & 0 & 0 & 2 & 0 & 0 \\
\hline & $0(8)$ & 8 & $8 \cdot 5$ & 0 & 12 & 0 & 0 & 0 \\
\hline & $0(4)$ & 10 & 10 & 0 & & & & \\
\hline & 0 & 9 & 7 & 2 & & & & \\
\hline
\end{tabular}


Table 3. (cont.)

\begin{tabular}{|c|c|c|c|c|c|c|c|c|}
\hline \multirow{2}{*}{$\begin{array}{l}4 \text { th Reagent } \\
\text { constituents }\end{array}$} & \multicolumn{4}{|c|}{ ALUPE } & \multicolumn{4}{|c|}{ TUMU TUMU } \\
\hline & SG & FG & $\mathrm{F} / \mathrm{S}$ & 4 th & SG & $\mathrm{FG}$ & $\mathrm{F} / \mathrm{S}$ & 4 th \\
\hline & 3 & 12 & 11 & 0 & & & & \\
\hline & $0(10)$ & 10 & 11 & 0 & & & & \\
\hline & 0 & 10 & 11 & 0 & & & & \\
\hline \multirow{11}{*}{$\mathrm{SG}+\mathrm{F} 7$} & 0 & 12 & 13 & 0 & $9 \cdot 5$ & 0 & 0 & 0 \\
\hline & 0 & 5 & $13 \cdot 5$ & 0 & 11 & 0 & 0 & 0 \\
\hline & 0 & 3 & $8 \cdot 5$ & 0 & 6 & 6 & 2 & 0 \\
\hline & 0 & 3 & 15 & 0 & 9 & 0 & 11 & 0 \\
\hline & 5 & 13 & 0 & 0 & 12 & 4 & 0 & 0 \\
\hline & 7 & 12 & 0 & 0 & $12 \cdot 5$ & 10 & 4 & 0 \\
\hline & $10 \cdot 5$ & 3 & 3 & 0 & & & & \\
\hline & 12 & 11 & $9 \cdot 5$ & 0 & & & & \\
\hline & $9 \cdot 5$ & 11 & 4 & 0 & & & & \\
\hline & 10 & 10 & $8 \cdot 5$ & 0 & & & & \\
\hline & $9 \cdot 5$ & 5 & 3 & 0 & & & & \\
\hline
\end{tabular}

Figures in parentheses are the results of tests with SG alone carried out several months later.

difference $(p<0.0001)$ between the 2 Bombay centres and the 4 other centres. See bottom of Table 4 .

Distant suppression of the SG reagent was observed in $110(33 \%)$ of the 37 category 1 and 3 individuals as shown in Table 5. (Not included in the results are those persons at AHRI/ALERT who were tested at the fourth site with the fractions of M.vaccae alone.) SG suppression occurred in 5/43 of those who received a half dose of $S G$ (taken as a control value): 20/44 who received $\mathrm{SG}+\operatorname{Vaccin}(p<0.001) ; 5 / 22$ who received SG+Leprosin A (ns); 14/37 who received SG + Chitin $(p<0.007) ; 11 / 46$ who received $\mathrm{SG}+\mathrm{F} 2(p<0 \cdot 005) ; 11 / 26$ who received SG $+\mathrm{F} 4(p<0.005) ; 13 / 35$ who received SG + F5 $(p<0.01) ; 19 / 46$ who received $\mathrm{SG}+\mathrm{F} 6(p<0 \cdot 002)$ and $12 / 38$ who received $\mathrm{SG}+\mathrm{F} 7(p<0 \cdot 03)$.

All fourth reagents tested in Kopri showed significant distant suppression although unfortunately the control reagent $\mathrm{SG}+$ saline was not tested in this place. These results are in sharp contrast with those for Vimala, this difference being very highly significant $(p<0 \cdot 00001)$. With the exception of $\mathrm{SG}+$ Vaccin no significant distant suppression occurred in AHRI/ALERT, however reagents containing F4 and F7 were not tested there. As in India the two Kenyan centres show striking differences in that none of the fractions produce distant suppression in Tumu Tumu, whereas suppression is significant with fractions 5 and 6 in Alupe 
Table 4 Numbers of individuals with a positive response to SG who exhibit local suppression of $\mathrm{F} / \mathrm{S}$ and 4 th reagent mixtures by area and composition of 4 th reagents.

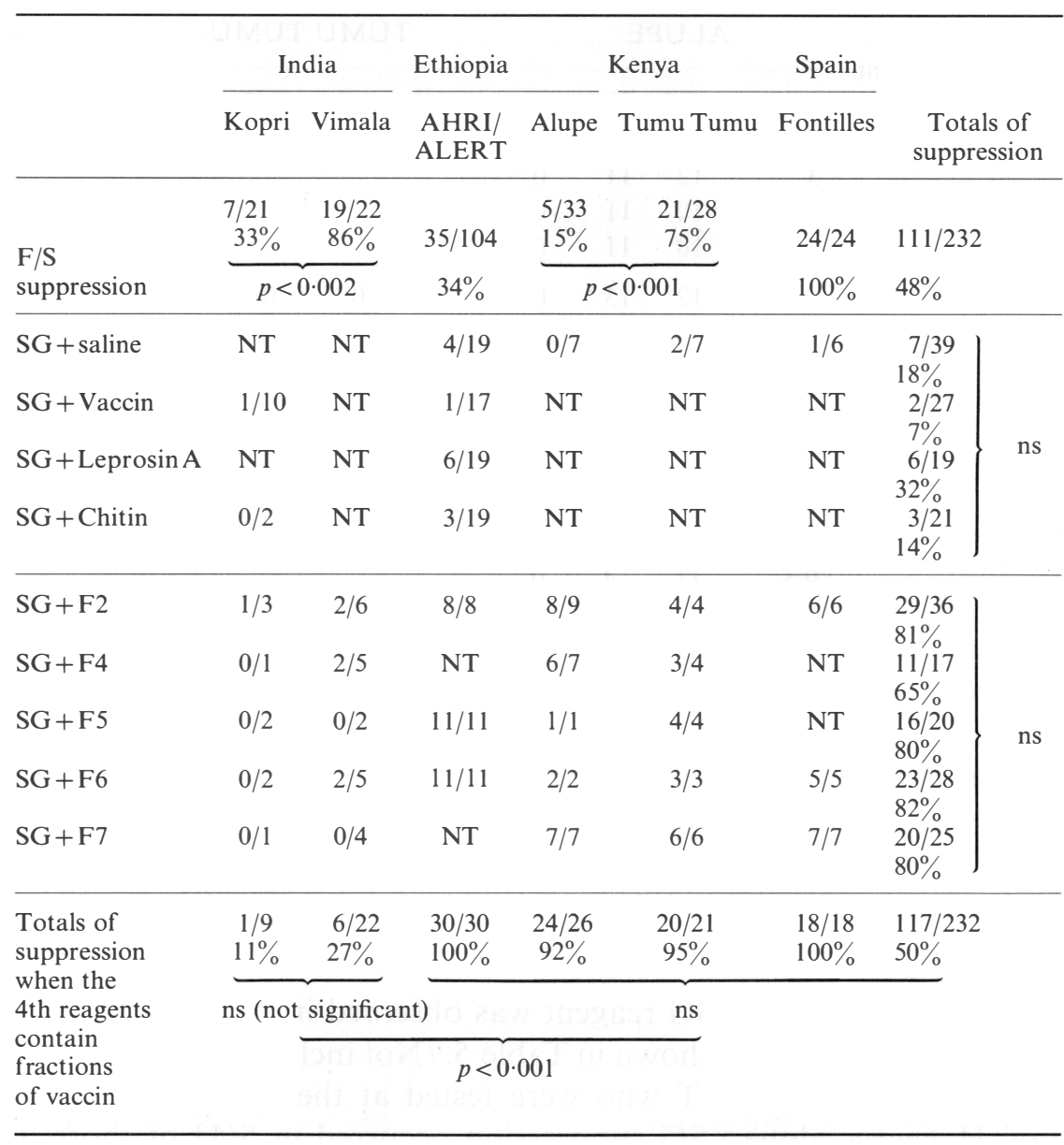

$\mathrm{NT}=$ Not tested

$(p<0 \cdot 001)$. There was no evidence of distant suppression with the 3 fractions tested in Spain.

\section{Discussion}

There are many ways of analysing the very complicated data obtained. The results confirm the principles of our previous investigations and demonstrate both local and distant suppression associated with mycobacterial extracts. These suppressor functions appear to be associated with different determinants and 
Table 5. Number and percentage of individuals in skin test responder categories 1 and 3 showing distant suppression of the response to the SG reagent grouped according to location and the constitutents of the 4 th reagent.

\begin{tabular}{|c|c|c|c|c|c|c|c|}
\hline & In & & $\underline{\text { Ethiopia }}$ & & enya & Spain & \\
\hline & Kopri & Vimala & ALERT & Alupe & Tumu Tumu & Fontilles & Total \\
\hline $\mathrm{SG}+$ Saline & NT & NT & $2 / 21$ & $1 / 8$ & $1 / 8$ & $1 / 6$ & $\begin{array}{l}5 / 43^{*} \\
12 \%\end{array}$ \\
\hline $\mathrm{SG}+$ Vaccin & $9 / 18$ & NT & $\begin{array}{l}11 / 26 \\
p<0 \cdot 005\end{array}$ & NT & NT & NT & $\begin{array}{l}20 / 44 \\
45 \% \\
p<0.001\end{array}$ \\
\hline $\mathrm{SG}+$ Leprosin A & NT & NT & $\begin{array}{l}5 / 22 \\
\text { ns }\end{array}$ & NT & NT & NT & $\begin{array}{l}5 / 22 \\
23 \% \\
\text { ns }\end{array}$ \\
\hline $\mathrm{SG}+$ Chitin & $11 / 15$ & NT & $\begin{array}{l}3 / 22 \\
\text { ns }\end{array}$ & NT & NT & NT & $\begin{array}{l}14 / 37 \\
38 \% \\
p<0.007\end{array}$ \\
\hline $\mathrm{SG}+\mathrm{F} 2$ & $\begin{array}{c}9 / 10 \\
p<0.001\end{array}$ & $0 / 6$ & $\begin{array}{l}0 / 9 \\
\text { ns }\end{array}$ & $\begin{array}{l}1 / 10 \\
\mathrm{~ns}\end{array}$ & $1 / 5$ & $0 / 6$ & $\begin{array}{l}11 / 46 \\
24 \% \\
p<0.005\end{array}$ \\
\hline $\mathrm{SG}+\mathrm{F} 4$ & $\begin{array}{l}8 / 8 \\
p<0.001\end{array}$ & $1 / 6$ & NT & $\begin{array}{l}2 / 8 \\
\mathrm{~ns}\end{array}$ & $0 / 4$ & NT & $\begin{array}{l}11 / 26 \\
42 \% \\
p<0.005\end{array}$ \\
\hline $\mathrm{SG}+\mathrm{F} 5$ & $\begin{array}{l}5 / 8 \\
p<0 \cdot 005\end{array}$ & $0 / 3$ & $\begin{array}{l}0 / 12 \\
\text { ns }\end{array}$ & $\begin{array}{l}8 / 8 \\
p<0 \cdot 001\end{array}$ & $0 / 4$ & NT & $\begin{array}{l}13 / 35 \\
37 \% \\
p<0 \cdot 01\end{array}$ \\
\hline $\mathrm{SG}+\mathrm{F} 6$ & $\begin{array}{l}8 / 9 \\
p<0.001\end{array}$ & $0 / 5$ & $\begin{array}{l}1 / 12 \\
\mathrm{~ns}\end{array}$ & $\begin{array}{l}10 / 10 \\
p<0 \cdot 001\end{array}$ & $0 / 5$ & $0 / 5$ & $\begin{array}{l}19 / 46 \\
41 \% \\
p<0.002\end{array}$ \\
\hline $\mathrm{SG}+\mathrm{F} 7$ & $\begin{array}{l}6 / 7 \\
p<0.001\end{array}$ & $2 / 7$ & NT & $\begin{array}{l}4 / 11 \\
\text { ns }\end{array}$ & $0 / 6$ & $0 / 7$ & $\begin{array}{l}12 / 38 \\
38 \% \\
p<0.03\end{array}$ \\
\hline & $\begin{array}{l}36 / 42 \\
86 \%\end{array}$ & $\begin{array}{l}3 / 27 \\
11 \%\end{array}$ & & $\begin{array}{l}25 / 47 \\
53 \%\end{array}$ & $\begin{array}{l}1 / 24 \\
4 \%\end{array}$ & & $\begin{array}{l}110 / 337 \\
33 \%\end{array}$ \\
\hline & $p<0.0$ & & & $p<0$ & & & \\
\hline
\end{tabular}

* Control value for statistical analyses.

individuals vary in their responses to them. This variation depends on geographical location and the degree of sensitization to mycobacteria. BCG status and whether or not the individual is being treated for leprosy do not affect the results significantly, but a true appraisal of this requires further study. Racial effects that could not be ruled out in our previous studies, appear not to have 
influenced the present data since quite different results have been obtained from different centres within the same racial areas (see Table 3 ).

Taken as a whole, both local and distant suppression can be associated with each of the fractions, although the effects vary geographically. Local suppression occurred with all fractions at the African and Spanish centres, but not at all at the Indian centres (Table 4). On the other hand local suppression by the complete $\mathrm{F} / \mathrm{S}$ reagent occurred in one Indian centre, Vimala, but not the other, and in one Kenyan centre, Tumu Tumu, but not the other. Distant suppression associated with all the fractions was found at Kopri, but not Vimala; the reverse of local suppression by F/S. Distant suppression was also found at Alupe, but only associated with fractions 5 and 6 , and not at Tumu Tumu; again the reverse of local suppression by $\mathrm{F} / \mathrm{S}$.

Purely local suppression is seen most clearly amongst the staff members of Sanatorio de Fontilles (see Tables 2 and 4) where the F/S mixture never produced a positive reaction and all 3 fractions tested also induced local suppression.

Our data shows very little relationship between the 2 types of suppression, strongly suggesting that different determinants are involved.

Leprosy patients were included in our study groups in Bombay and Ethiopia. Those tested in Alupe and Fontilles, were leprosarium staff members and thus can be considered as contacts of the disease. Tumu Tumu is a general hospital in an area of low leprosy endemicity, thus those tested were unlikely to have had more than occasional contact with leprosy. In view of this it remains possible that distant suppression may be associated with clinical leprosy or contact with it, but the results from Tumu Tumu make it unlikely that local suppression is leprosy associated.

The importance of the results obtained, although they are complicated and difficult to assimilate, is straightforward. Mycobacteria have been shown to possess immune suppressor activities of 2 types varying in their effects from place to place. If the leprosy bacillus itself possesses these functions then they may well be the essential mechanisms for immunosuppression required for successful infection local suppression and for the pathogenesis of multibacillary leprosy distant suppression. Our first attempts to demonstrate these functions in $M$. leprae with the combination of SG + Leprosin A failed, but more extensive studies and the preparation of fraction of Leprosin A are obviously essential.

\section{Acknowledgements}

We should like to thank the patients and staff of the centres where our studies were carried out for their willing participation. We are also grateful to Dr R J W Rees for providing the Leprosin A. Our thanks are also due to Lepra for extensive support and to the British Council and the Medical Research Council for additional financial assistance. 


\section{References}

' Stanford JL, Nye PM, Rook GAW, Samuel NM, Fairbank A. A preliminary investigation of the responsiveness or otherwise of patients and staff of a leprosy hospital to groups of shared or species specific antigens of mycobacteria. Lepr Rev, 1981; 52: 321.

2 Nye PM, Price JE, Revankar CR, Rook GAW, Stanford JL. The demonstration of two types of suppressor mechanism in leprosy patients and their contacts by quadruple skin testing with mycobacterial reagent mixtures. Lepr Rev, 1983; 54: 9.

3 Morton A, Nye PM, Rook GAW, Samuel N, Stanford JL. A further investigation of skin test responsiveness and suppression in leprosy patients and healthy school children in Nepal. Lepr Rev, 1984; 55; 273. 